\title{
Nous, on se sauve nous-mêmes. Sécularisation, identité paysanne et écologie
}

\author{
Luis Martínez Andrade \\ (iD) https://orcid.org/oooo-0002-5000-9033 \\ Collège d'études mondiales/FMSH, Francia \\ luisma_andrade@hotmail.com
}

Mathieu Gervais, Nous, on se sauve nous-mêmes. Sécularisation, identité paysanne et écologie, Van Dieren éditeur, Paris, 2020, 361 pp.

En este apasionante libro, el politólogo francés Mathieu Gervais rastrea tanto los diversos elementos (utópicos e históricos) como las diferentes influencias (políticas y religiosas) que contribuyen a la configuración del actual movimiento campesino alternativo en Francia. Dicho movimiento, compuesto principalmente por campesinos que practican una agricultura familiar, se opone al modelo productivista de la modernidad capitalista. A partir de una perspectiva interdisciplinaria, Gervais aborda, a través de la agricultura campesina, las tensiones y los cambios en el mundo rural con la finalidad de ponderar el papel de la religión como recurso espiritual, ético, cultural e, incluso, político. En ese sentido, y como bien lo consigna en el prólogo el investigador Philippe Portier, la perspectiva de Gervais da cuenta de la evolución del universo agrícola, así como de la transformación de las adhesiones religiosas (p.14) del mundo rural.

La primera parte, "Une histoire religieuse de la modernisation agricole”, está compuesta por dos capítulos en los que el autor examina el proceso de modernización de la agricultura francesa e identifica el papel del catolicismo como vector de la politización del movimiento campesino. En el primer capítulo, Gervais observa la manera cómo, durante la Tercera República francesa (1870-1940), se configuró la identidad campesina en función de una ideología conservadora en la que la oposición ciudad/campo ocultaba las relaciones capitalistas de dominación. Sin embargo, a

Esta obra está protegida bajo una Licencia Creative Commons Atribución-No Comercial 4.0

Internacional

Secuencia. Reseñas, 2021

http://secuencia.mora.edu.mx
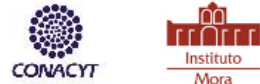
finales de la década de los cuarenta del siglo pasado y con la creación de la Fédération Nationale des syndicats d'exploitants agricoles (FNSEA), empezó a surgir un discurso crítico sobre el uso de la técnica y sobre la relación con la naturaleza. Por otra parte, la emergencia del nuevo pensamiento cristiano representado en los trabajos de Jacques Maritain (1882-1973), de Emmanuel Mounier (1905-1950) y de Louis-Joseph Lebret (1897-1966) y del giro de 1943 de los movimientos de Acción Católica contribuyeron a la reinvención de la identidad campesina, puesto que la "noción de ideal histórico concreto", la necesidad de involucrarse en lo social y el compromiso en el mundo profano orilló a los creyentes a participar activa y políticamente en la sociedad. ${ }^{1} \mathrm{Al}$ respecto, el papel de la Jeunesse Agricole Catholique (JAC) es significativo, ya que expresó no sólo el diálogo con el mundo moderno sino también el proyecto de cristianizar a la modernidad (p. 49). Es por ello que la JAC se constituyó como un vector importante de la transformación del mundo rural. Posteriormente, con el advenimiento de la "Revolución silenciosa" (proceso en el que los agricultores presentan reivindicaciones ligadas a su condición socio-económica) y de la búsqueda de reconocimiento por parte de los campesinos, se transformó la espiritualidad de la JAC. Esta segunda generación de jacistas (miembros de la JAC) identificada con el movimiento de Jeunes Agricultures (Jóvenes Agricultores), por un lado, promovió un eje social (una tercera vía entre el comunismo y el capitalismo) y, por el otro, fomentó un eje centrado en la racionalidad económica. Notamos pues una reconfiguración de la identidad campesina (tradicionalista durante la Tercera República y progresista en los setenta) y una aceptación ambivalente del mundo moderno en el seno del movimiento de Jeunes Agricultures.

En el segundo capítulo, el autor examina el catolicismo como vector de la politización. Retomando la idea del Momento 68' (Pelletier, 2002, p. 85) y sus implicaciones no sólo sociales sino también ideológicas, Gervais reconoce un proceso de radicalización en el mundo rural.² Efectivamente, el análisis marxista de las condiciones materiales de existencia posibilitó entender tanto las relaciones de explotación, propias del capitalismo, como la importancia de la lucha de clases en la transformación de la realidad social. Sobre este punto, el autor aborda la figura

\footnotetext{
${ }^{1}$ En lo que respecta al papel de este nuevo pensamiento cristiano y su recepción en América Latina, concretamente en Brasil, véase las excelentes investigaciones de Gómez de Souza (1984); Löwy (2019). 2 Por otra parte, no se puede soslayar que el Momento 68' fue fundamental para el proceso de radicalización del Mouvement Rural de Jeunesse Chrétienne (MRJC). El papel del teólogo Jean-Yves Jolif fue crucial en la crítica del capitalismo. 
carismática -en sentido weberiano del término- de Bernard Lambert (1931-1984) pues este sindicalista agrícola, por un lado, representó una ruptura con el consenso modernizador de la segunda generación jacista y, por el otro, encarnó el florecimiento de una nueva generación de líderes de la nueva izquierda campesina. Secretario general del Centre national des jeunes agriculteurs (CNJA) en 1957, Lambert fue un defensor de la autodeterminación de Argelia en 1959. Cristiano y marxista a la vez, este sindicalista agrícola publicó en 1970 su obra Les paysans dans la lutte des classes (Los campesinos en la lucha de clases) y, un par de años más tarde, fue uno de los principales promotores de la creación sindical alternativa llamada Paysans-travailleurs (PT). Huelga decir que esta organización sindical (PT) fue creada por una parte de la disidencia de la FNSEA y de la CNJA. Sin embargo, a raíz del proyecto de ampliación del campo militar en el altiplano del Macizo Central de Larzac, Lambert fue uno de los principales protagonistas de la movilización en 1973 contra dicho proyecto gubernamental. La movilización de Larzac fue crucial tanto para la rehabilitación del campesinado como fuerza anticapitalista como para la conformación de una nueva izquierda rural expresada en 1987 con la fundación de la Confédération paysanne. 3 Además, el papel de las revistas, tanto para el proceso de formación de cuadros como para la discusión de las ideas y reivindicaciones del mundo rural, fue otro elemento de capital importancia. Cierto, a finales de los años cincuenta un grupo de estudiantes franciscanos, marcados por la conferencia de Bandung de 1955, fundaron la revista Frères du Monde en la que se denuncia clara y abiertamente al capitalismo (número de octubre de 1968), sin embargo, es por medio de las revistas Paysans en lutte (19701974), Vent d'Ouest y Nouvelles campagnes que la crítica de la agricultura capitalista se articuló a las preocupaciones ecológicas. Durante la década de los setenta, asistimos a un proceso de desacralización de la naturaleza que tuvo fuertes implicaciones en el imaginario rural pues el hombre es ahora concebido como el responsable de la historia. Por tanto, nos dice Gervais (p.105), a partir de la década de los setenta somos testigos de una transformación -provocada por la decepción del progreso técnico- de la tradición campesina en la que emerge una nueva concepción del cristianismo, más individual y menos ligada a la Iglesia y, en cierto sentido, más Cristocentrada. Durante la década de los ochenta, el vínculo entre la nueva izquierda campesina y la ecología es

\footnotetext{
3 Para conocer de manera profunda los antecedentes de la Confédération paysanne véase (Bové y Dufour, 2001). 
cada vez más nítido y, por tanto, el término de Agriculture paysanne estuvo ligado a la Confédération paysanne.

La segunda parte, "Religion et politique dans l'agriculture paysanne" contiene un par de capítulos en los que el autor nos propone una lectura socio-histórica de la práctica y de los compromisos ecológicos contemporáneos de los agricultorescampesinos. En el tercer capítulo y apoyado sobre un trabajo de terreno netamente sociológico (cuestionarios, entrevistas semidirigidas in situ, historias de vida), Gervais aborda el perfil de militantes tanto héritiers (herederos) como néoruraux (neorrurales) para develar un contexto de secularización religioso (disminución de la práctica católica) y político (relativización del referente marxista). A través del caso de Patrice (héritier) y de Arthur (néoruraux), el autor muestra, de manera brillante, la relación entre rupturas biográficas de los sujetos/entrevistados y la historia social con la finalidad de colocar dos temáticas (búsqueda de coherencia e ideal ético) que le permiten explicar su tesis de la eticización del compromiso (éthicisation de l'engagement) de y en la agricultura campesina. Además, el autor subraya el hecho que la relación con la naturaleza trastoca la dimensión política (desplazamiento del referente marxista por el referente ambiental), la dimensión religiosa (alejamiento de la Iglesia) y la dimensión agrícola (promoción de trayectorias culturales distintas) en el imaginario campesino. En ese orden de ideas, Gervais nos propone un ejercicio de sociología religiosa de los agricultores-campesinos en la que destaca la construcción de ciertos tipos-ideales: cristianos (herederos de Acción Católica, sensibles al principio de apertura y familiarizado con los movimientos del Gran Oeste francés), convertidos (simpatizantes de la Association pour le maintien d'une agriculture paysanne-AMAP pero que mantienen su distancia con el término de campesino), campesinos con una "espiritualidad" (sensibles al discurso propuesto por autores como Masanobu Fukuoka o Pierre Rabhi), no-creyentes (influenciados por la movilización de Larzac y de la lucha contra la energía nuclear) y buscadores de sentido (de sensibilidad ecológica y libertaria). El tema de la sacralización de la naturaleza o de la sistematización de las ontologías es retomado por el autor para ilustrar la división entre dos grupos o sensibilidades en el seno de los agricultores-campesinos, por un lado, aquellos que siguen convencidos de la separación entre cultura y naturaleza pero pugnan por una humanización de la naturaleza y, por el otro, aquellos que vislumbran una desnaturalización en la que la relación con la vida no-humana que está en sintonía con el movimiento New Age. La influencia del discurso cristiano nos dice el autor (p.244), 
se puede observar en la temática del respeto por la vida y, por tanto, la crítica de los organismos genéticamente manipulados (OGMs) expresa el rechazo de transformar lo viviente. Dicha rehabilitación de lo sagrado confirmaría pues la tesis de un desplazamiento del arsenal teórico marxista a una ecología espiritual, por no decir, espiritualista (Rudolf Steiner).

Finalmente, en el último capítulo, el autor analiza la relación entre los agricultores-campesinos y la política. Apoyándose en los aportes de algunos politólogos como Daniel Boy, el autor plantea la pregunta de si podemos considerar a la ecología como una nueva cultura política. Para responderla, Gervais echa mano de su trabajo de campo y reconoce en el grupo identificado con la extrema izquierda campesina tres elementos (característicos de la ecología): el anti-productivismo (expresión de una renovación del discurso marxista que pone en cuestión la lógica lucrativa del capitalismo), la autonomía (ligada a la autonomía alimentaria y energética) y la solidaridad (local como global). Por consiguiente, el autor concluye que el apego a la ecología corre en paralelo a una identificación con la cultura política de izquierda por parte de la agricultura campesina. De esta manera, las redes de la agricultura campesina siguen siendo estructuradas de acuerdo con las referencias ligadas a culturas políticas católicas de izquierda y ecológicas, también de izquierda. Por otra parte, en este capítulo el autor desarrolla su tesis de la eticización del compromiso como una nueva agencia entre subjetividad y objetividad, esfera privada y esfera pública e, incluso, profana y sagrada. En otras palabras, el compromiso de los agricultores-campesinos es estimulado por la crítica del "vacío" ontológico de la condición moderna, pero dicho posicionamiento no mina la subjetividad individual, ni tampoco produce un olvido del Yo en beneficio de dogmas colectivos, sean estos religiosos o políticos. Este punto nos parece de sumo interés para el estudio del proceso de subjetividad en los movimientos sociales, ya que la valorización de la soberanía individual y de la realización del Yo se fortalecen en la lucha en común.

El trabajo de Mathieu Gervais es una valiosa aportación para la sociología de la religión puesto que no se trata de afirmar "el retorno de lo religioso" sino, precisamente, de mostrar el regreso de la "cuestión religiosa" (Pelletier, 2019), en este caso, en el estudio del mundo rural. Pero, además, su libro contribuye a la rehabilitación de otros saberes (Stengers, 2020) que confrontan la dinámica destructora de la modernidad capitalista. En un acápite dedicado a "la emergencia de una palabra campesina”, el autor subraya la importancia de la lucha de Larzac, que al 
poner fin al "complejo campesino", fue la expresión de un proceso decolonial, puesto que la modernidad había colocado al campesino en una situación de inferioridad. Por nuestra parte y a la luz de las protestas e insurrecciones, protagonizadas principalmente por campesinos e indígenas, en contra de los megaproyectos extractivistas en América Latina nos preguntamos si acaso no será el momento para que los investigadores postcoloniales y decoloniales reconozcan que detrás de las movilizaciones contra la dinámica extractivista se encuentra también el componente de clase.

\section{Referencias}

Bové, J. y Dufour, F. (2001). El mundo no es una mercancía. Barcelona: Icaria.

Gómez de Souza, L. A. (1984). A JUC. Os estudantes católicos e a política. Petrópolis: Vozes.

Löwy, M. (2019). La Lutte des dieux. Christianisme de la libération et politique en Amérique latine. Paris: Van Dieren.

Pelletier, D. (2002). La crise catholique. Religion, société, politique. Paris: Payot.

Pelletier, D. (2019). Les catholiques en France de 1789 à nos jours. Paris: Albin Michel.

Stengers, I. (2020). Réactiver le sens commun. Paris: La découverte. 